\title{
Optical absorption spectrum of Cu2O-CaO-P2O5 glasses
}

\begin{abstract}
Homogeneous $\mathrm{CaO}-\mathrm{P} 2 \mathrm{O} 5$ and $\mathrm{Cu} 2 \mathrm{O}-\mathrm{CaO}-\mathrm{P} 2 \mathrm{O} 5$ glasses were prepared using a meltquenched method under controlled conditions. The binary glasses were found to be colourless and transparent while the ternary glasses changed from light green to dark green as the $\mathrm{Cu} 2 \mathrm{O}$ content increased. From the absorption edge studies, the values of the optical band gap, Eopt and Urbach energy, $\Delta \mathrm{E}$ were evaluated. The position of the absorption edge and hence the optical band gap were found to depend on the glass composition. Analysis of the optical band gap shows that for the binary glasses, the value increases as the content of $\mathrm{CaO}$ decreases, while for the ternary glasses, the value of the optical band gap increases as the content of the $\mathrm{Cu} 2 \mathrm{O}$ decreases. The density of the glasses was also measured and was found to increase with the increase in $\mathrm{CaO}$ and $\mathrm{Cu} 2 \mathrm{O}$ contents.
\end{abstract}

Keyword: A. Glass, A. Optical materials, D. Optical properties 